\title{
Levels of Consciousness
}

\author{
Wojciech Pisula \\ Institute of Psychology, Polish Academy of Sciences, Warsaw, Poland \\ Email: wojciech.pisula@psych.pan.pl
}

Received 26 October 2015; accepted 15 February 2016; published 18 February 2016

Copyright (C) 2016 by author and Scientific Research Publishing Inc.

This work is licensed under the Creative Commons Attribution International License (CC BY).

http://creativecommons.org/licenses/by/4.0/

c. (i) Open Access

\begin{abstract}
Consciousness attracts the attention of researchers representing various disciplines. Hence, there is a demand for a theoretical tool that could integrate data and theoretical concepts originating from distinct fields. The paper proposes to use the framework of the theory of integrative levels. The development and the definitions of the concept of levels are briefly discussed. The final part of the paper presents a proposal for incorporating the levels of consciousness into the framework of the integrative levels theory.
\end{abstract}

\section{Keywords}

Integrative Levels, Consciousness, Levels of Consciousness, Animal Consciousness

\section{Introduction}

Whether animals are conscious is an important issue in science and philosophy: a present day intellectual challenge, especially in the West, which is still under a powerful influence of the Cartesian worldview. Animal consciousness, like their ability to think, communicate, bond, experience emotion or invent abstract concepts may be the last stronghold of the so-called uniquely human characteristics. This is especially apparent when comparative analysis of humans and animals is attempted. Perhaps, though, there is no need to topple that stronghold. Maybe it would be of some value to look at theoretical tools that could help us sidestep the problems resulting from intentional or accidental application of rules governing discrete variables to the phenomenon of consciousness. This paper attempts to implement the theory of integrative levels, as a methodological tool of organizing the knowledge about various forms and levels of consciousness.

\section{What is Consciousness: A Brief Outline of Problems with Definitions}

One of the most interesting explorations of the difficulties in defining consciousness was penned by Velmans (2009). I do not intend to recount all of the assertions in his article, however, Velmans makes it clear that the term "consciousness" is used in a plethora of theoretical contexts, hence the need to establish its proper meaning 
in a given discourse. Incidentally, the same is true of numerous of terms used in psychology. Despite these difficulties, some elements found in different definitions of consciousness are fairly stable. First and foremost, the subject is "conscious" of something. Being conscious of "something" usually amounts to experience. Experiences can vary from pure sensations to higher forms of experiencing one's feelings and thoughts. Again, Morgan's statements quoted above seem very relevant. Colloquial meanings notwithstanding, consciousness can be described as a certain kind of knowledge subjects have about their feelings, thoughts, and desires. The higher forms of consciousness described in literature, such as self-awareness, can equally well be described as the subjects self-knowledge. And from there, only a small step leads to the famous "Cogito ergo sum".

In the opening lines of the chapter on the wave of consciousness in his famous monograph "Introduction to comparative psychology", L.C. Morgan offers a telling account of difficulties in defining consciousness (Morgan 1894: p. 11): I DO not propose to begin by defining consciousness. Any definition would be found, when analysed, to, involve a direct reference to primary experience. I shall therefore assume that my reader has this primary experience; that he is conscious, and that he knows what I mean when I say that he is conscious. And I ask him to verify in his own experience the preliminary statements which I make in this chapter. The first of these is that we are only directly aware of Present states of consciousness. I use the word "present," not in its abstract sense of an ideal boundary between past and future, but as descriptive of a short but not inappreciable period of time. I shall speak of this short period of time as the moment of consciousness.”. Morgan's conclusions seem to be more relevant today than ever.

This model posits multiple continuous dimensions (Figure 1). From the level of arousal/alertness, through the continuum of content complexity, we are presented with degrees of consciousness on a continuum, resulting in the level of its organisation (form). As attractive as this analysis seems to be for a number of reasons (such as formal elegance), the problem of meeting certain criteria, classifying or simply arranging phenomena reveals the full extent of weaknesses in such an ideally conceived continuity. For practical or theoretical reasons, we are often compelled to determine whether a given individual is asleep or awake. Thus we must face the problem of representing consciousness as a quantitative (Cf. Northoff, 2013) or discrete variable (states of consciousness). Language has labels to describe certain states of the dimension of interest. For example, we speak of parameters having low, medium or high levels. We are thus mentally converting a quantitative variable to a discrete one or, at times, even a qualitative one. Often when describing phenomena, we say that a quantitative change turns into a qualitative one. Inevitably, in our thinking of consciousness we move away from treating it as a perfect continuum, and towards defining states and levels of consciousness.

\section{Levels of Consciousness-Step I}

The idea of levels of psychical faculties was first comprehensively outlined by L.C. Morgan (1894). His book continues to serve as an important point of reference for comparative psychology. Morgan's work is probably most famous for establishing the principles for interpreting the complexity of animal psychology. The main rule, referred to as Morgan's canon, states that if a given behavioral phenomenon can be explained in terms of lower order processes, it should not be described or interpreted in terms of higher order phenomena (p. 53). Although

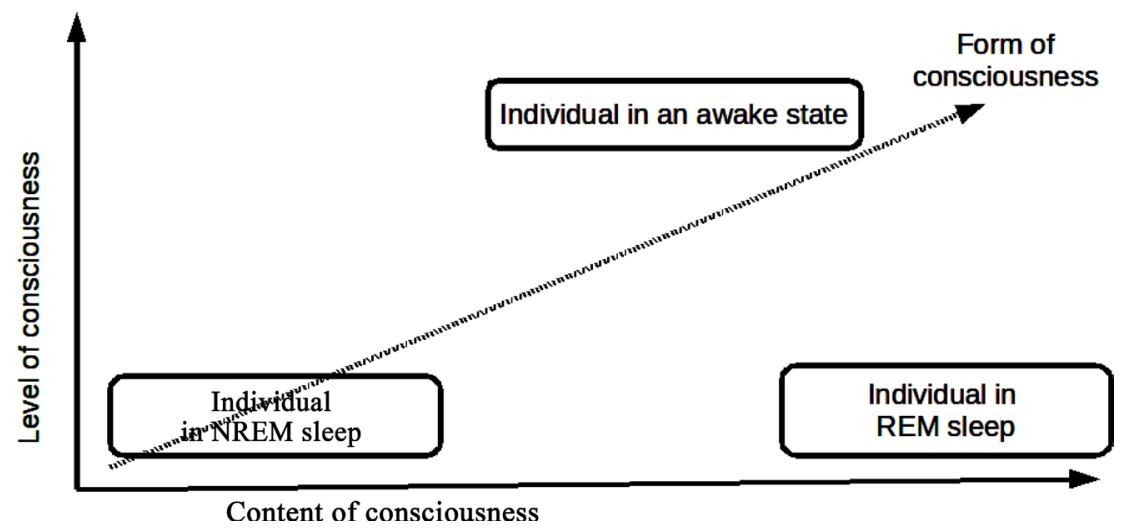

Figure 1. Relationships between arousal, the content of consciousness and its form according to Northoff (modified from Northoff, 2013). 
the implications of unreserved acceptance of Morgan's cannon for comparative psychology are beyond the scope of this article, it should be noted that they were quite significant. The very formulation of the rule hints at the concept of levels. Morgan notes that we can speak in terms of higher and lower order processes. Morgan's reasoning is permeated with the idea of levels, albeit not clearly defined. The argument on page 57 seems to suggest that the notion of a level is supposed to define an objectively measurable (and thus capable of being compared) level of development of a given psychological function. Morgan was well aware of the implications of positing objectively existing levels of developmental/evolutionary advancement.

To avoid misrepresenting the argument, here it is in its entirety. Morgan, 1894: p. 57: "There would appear to be three possible methods, which are exemplified in Figure 2. Let a represent the psychical stature of man, and $1,2,3$, ascending faculties or stadia in mental development. Let $\mathrm{b}$ c represent two animals the psychical stature of each of which is to be gauged. It may be gauged first by the "method of levels," according to which the faculties or stadia are of constant value. In the diagram, b has not quite reached the level of the beginning of the third or highest faculty, while c has only just entered upon the second stadium. Secondly, it may be gauged by the "method of uniform reduction." In both b and c we have all three faculties represented in the same ratio as in a, but all uniformly reduced. And thirdly, it may be gauged by the " method of variation," according to which any one of the faculties 1,2 , or 3, may in b and c be either increased or reduced relatively to its development in a. Let us suppose, for example, that $b$ represents the psychical stature of the dog. Then, according to the interpretation on the method of levels, he possesses the lowest faculty (1) in the same degree as man; in the faculty (2) he somewhat falls short of man; while in the highest faculty (3) he is altogether wanting. According to the interpretation on the method of uniform reduction he possesses all the faculties of man but in a reduced degree. And according to the interpretation on the method of variation he excels man in the lowest faculty, while the other two faculties are both reduced but in different degrees".

Obviously, Morgan considers the last approach he mentions to be the correct one. In hindsight, we can appreciate the competence of his reasoning. With reference to consciousness in particular, Morgan unequivocally insists on its developmental character. According to his approach, consciousness is an evolutionary phenomenon emerging from more basic phenomena (lower levels?), which he calls infra-consciousness (p. 335).

\section{Levels of Consciousness-Step II}

A significant development in comparative analysis theory occurred in the first half of 20th century with the publication of Ludwig Von Bertalanffy's general systems theory (1950) and James Feibleman's theory of integrative levels (1954). Bertalanffy's most significant contribution was to propose the alternative to the reductionist approach to the analysis of natural and psychological phenomena. The concept of the system defined as a whole

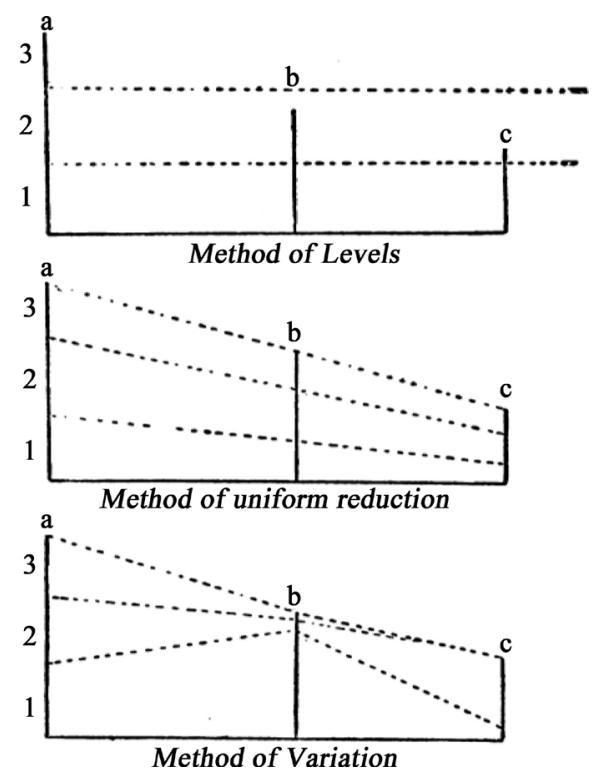

Figure 2. The original LC Morgan figure (1894). See text for description. 
consisting of lower level elements connected with one another through various types of feedback and relations opened new avenues for the analysis of phenomena studied by empirical sciences. As for James Feibleman (1954), he proposed a particularly interesting way of organising our knowledge of phenomena belonging to different levels of complexity/organisation, which he termed the Theory of Integrative Levels.

Integrative level is defined as a structural unit organising elements belonging to a lower level and adding a novel quality, granting a qualitatively new aspect to that level (Cf. Tobach, 1995; 2006). To be able to understand this way of analysing reality, we must first refer to the general statements of the theory of integrative levels present in the philosophy of science, which intended to regulate the relationships between various scientific disciplines. The key tenets of that theory were presented by James K. Feibleman (1954).

Some laws of the integrative levels (abbreviated and modified)

- Each level organizes the level or level below it plus one emergent quality. Thus, the integrative levels are cumulative upward. Chemical elements have mass, density and dimensions, and so do biological organisms. It is possible to weigh aluminum or to measure the height of a horse. But the everything has at least physical properties does not mean that anything except physical objects has only physical properties.

- Complexity of the levels increases upward. This low is corollary of the first. For if the levels are cumulative upward, each must be more complex than the one before it.

- In any organization the higher level depends upon the lower. A culture will not last if the cities are destroyed. The reverse is not true however. A man run over by a truck is no longer a man, no longer even an organism but merely a collection of decaying cells, eventually to be reduced to still lower levels, to carbon compounds.

- In any organization, the lower level is directed by the higher. Institutions may have physical perquisites, such as buildings and tools, but they take social aims. An army may travel on its stomach but it is its brain that tells it where to go.

- For an organization at any given level, its mechanism lies at the level below and its purpose at the level above. This low states that for the analysis of any organization three levels are required: its own, the one below and the one above. To analyze a mechanism we drop down one level. Similarly, to find the purpose of any organization we would move up one level, for then we are considering the organization as itself a part of some higher and more complex organization.

- A disturbance introduced into an organization at any one level reverberates at all levels it covers. We are assuming here, of course the levels as they occur in highly integrated organizations, such as living organisms. Mental events may cause physical difficulties and vice-versa.

- The time required for a change in organization shortens as we ascend the levels. Atoms and molecules have been around longer then cells, cell longer than more complex organisms and these longer then human cultures. Evidently, the more complex the organization the more unstable, so that advances are not achieved without a price and advanced positions are not easily held.

- The higher the level, the smaller its population of instances. Therefore, as we should expect, there are fewer molecules than atoms, fewer cells than molecules fewer organisms than cells and fewer cultures than organisms. From the point of view of population the integrative levels form a pyramid.

- It is impossible to reduce the higher level to the lower. Each level has its own characteristic structure and emergent quality. Hence, to reduce a higher to a lower level means to lose the quality and the structure of the higher level. A living organism is not merely a collection of tissues and cells and organs, although it contains these. The truth seems to be that the whole and its parts are equally real. The question of which is part and which is whole becomes merely a question of the level chosen for analysis.

- An organization at any level is a distortion of the level below. War is a social and cultural phenomenon, however it leads to the destruction of many living organisms and even more cells.

- Whatever is affected as an organization has some effect as an organization. Examples of characteristic behavior are: stimulus-response at psychological level and contact-adaptation and the cultural level.

The above laws yield a simple set of rules for explaining the phenomena of interest.

- The analysis of the phenomenon must be at the lowest level which will provide sufficient explanation.

- The reference of any organization must be to the highest level which its explanation requires.

- An organization belongs to its highest level.

- Every organization must be explained finally on its own level.

This analytical strategy is particularly relevant for complex phenomena characterized by varying levels of 
complexity. Scientific progress involves, among other things, identification of new integrative levels and sublevels of a given phenomenon.

\section{A Sample Application of the Theory of Integrative Levels-Exploratory Behavior}

The effectiveness of this approach was used in the analysis of a variety of exploratory behaviors in animals (Pisula, 1998). Exploratory behavior lends itself particularly well to this method of analysis, as it occurs in a variety of forms, from the simplest ones exhibited by the most primitive animals.

According to the theory of integrative levels, the forms of exploratory behavior can be approached as successive levels of the qualitative evolution of behavior. The function of a given behavior and the regulating mechanisms change depending on how advanced (integrated) is a given level. This is not any random change, however. It involves the addition of new qualities (on the side of functions and mechanisms) to the existing level. As such, enhanced integration translates to a qualitative, evolutionary change from the most basic to sophisticated forms. The main aspects of the integrative levels model of exploratory behavior are presented in Figure 3.

Figure 3 should be read bottom to top. It features a form of behavior not listed above. This is one of the most basic forms of an organism's response to an external stimulus-a positional response, which ethologists refer to as taxis. It is an innate, species-specific, fundamental form of behavior in simple organisms, consisting of actively assuming a body position with regard to a directional stimulus. Taxis is a stereotyped response to a specific stimulus. The organism acts like an automaton. The stimulus-response path is clearly defined. Thus the receptors receiving external stimuli can be said to control nervous system responses. This is not quite the case with the orienting reflex, which is a non-specific response, i.e. one that can be triggered by a wide range of environmental stimuli. Subsequent behavior is decided by the analysis of that stimulus which follows the occurrence of the orienting reflex. This is a case of receptors being controlled by the nervous system. Another piece of evidence in support of the contention that the orienting reflex is a qualitatively new behavior regulation process is the presence of habituation. The orienting response is subject to habituation via a process which, beyond any doubt, proves the involvement of neural systems capable of learning (Cf. Pisula, 2009). For that reason I poist neural control of receptors as a qualitative change differentiating taxis from the orienting reflex in the proposed approach to the study of exploratory behavior and related phenomena.

A higher level of organisation of exploratory behavior is locomotor exploration. General locomotor exploration typifies entering and moving through a new environment. The purpose of such behavior is to collect information about novel objects in the environment. A mechanism indispensable for the performance of that function

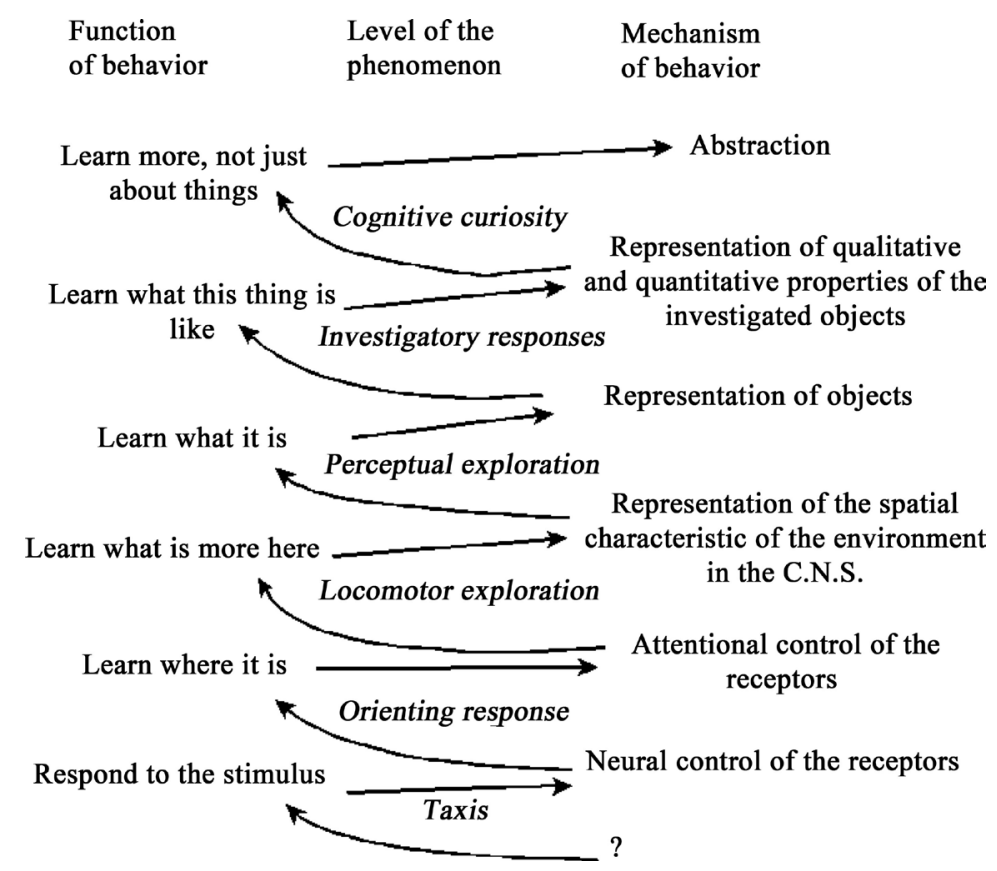

Figure 3. Exploratory behavior and related phenomena according to the theory of integrative levels. See text for description. 
must therefore be the ability to create spatial representations of familiar objects.

The next proposed integrative level is perceptual exploration. The purpose of perceptive exploration is object recognition/cognition. The mechanism that makes this possible is the ability to form mental representations of objects.

An advanced form of perceptual exploration is exploratory response. Exploratory responses are a group of exploratory behaviors oriented towards a specific stimulus. Their function is to provide information: answer the question "What is the explored object like?" The ability to create representations of the object's characteristics, both quantitatively and qualitatively, is a condition sine qua non for the nervous system to perform this role.

The highest integrative level of processes associated with exploration and related behavior is cognitive curiosity. This is undoubtedly the highest form of human activity, although the jury is still out whether it is exclusive to humans. The goal of cognitive curiosity is to collect information about the material and social environment, and about concepts that lack referents. Learning knowledge based not only on representations of actually existing objects is possible only via the ability to form abstract concepts.

The usefulness of the integrative levels approach is in the ability to generate theoretical hypotheses founded on a hierarchical structure and enabling us to incorporate their verification into the overall investigation of a particular phenomenon. And yet, this approach appears not to have been effectively applied to the study of other psychological phenomena, including consciousness.

\section{Levels of Consciousness-Step III-Proposed Model of Consciousness within the Integrative Levels Framework}

Current theories of consciousness often refer to the concept of levels. A good example is the work of A. Morin (2006), who attempts to combine a number of theoretical approaches to the study of consciousness. The approaches differ in the number and content of identified levels of consciousness, however, their outer limits are the same. The lowest level is nonconsciousness, which is characterised by a complete lack of the ability to be in touch with the world around. The other extreme is usually self-awareness and meta-consciousness-a term describing the state where the subject has available the information that he is a distinct subject experiencing reality (self-awareness) and that there are other individuals who possess a similar ability (meta-consciousness). The intermediary levels will be the subject of further analysis.

The model presented below is based on several assumptions derived from existing literature. First, there is a extensive consensus in terms of the two poles of consciousness (nonconsciousness vs. meta-consciousness). Second, consciousness has content (subjects are aware of something). Third, individual levels are presented in accordance with the principles posited by J. Feibleman (1954). For the sake of brevity, the proposed model is presented in tabular form (Table A1).

As noted by Feinberg and Mallatt (2013), the evolutionary processes that gave rise to consciousness phenomena started as long as 500 million years ago, with the emergence of vertebrates possessing midbrain. This shows that our thoughtless anthropocentrism is detrimental to our understanding of the world also with regard to consciousness. Due to limitations of space, the present proposal omits the ontogenetic perspective. However, there are reasons to believe that its inclusion would change little in the proposed construct, although it is very likely that higher integrative levels of consciousness would see further subdivision into constituent sublevels (Rochat, 2003). Is seems that the theory of integrative levels can still serve as a useful tool for advancing our understanding of complex phenomena. This paper presents an attempt to employ it in the analysis of the phenomenon of consciousness. We definitely need a theoretical tool to integrate interdisciplinary approaches of the research in the field of consciousness. One of the possible ways of achieving this goal is to put the integrative levels theory back to work.

\section{Acknowledgements}

1) The original version of this paper appeared in Polish in Przeglad Filozoficzny-Nowa Seria, vol. 24 (2).

2) This study was funded by the research project of The National Science Centre \#UMO-2013/09/B/HS6/ 03435.

\section{References}

Feibleman, J. K. (1954). Theory of Integrative Levels. British Journal for the Philosophy of Science, 5, 59-66. 
http://dx.doi.org/10.1093/bjps/V.17.59

Feinberg, T. E., \& Mallatt, J. (2013). The Evolutionary and Genetic Origins of Consciousness in the Cambrian Period over 500 Million Years Ago. Frontiers in Psychology, 4, 667. http://dx.doi.org/10.3389/fpsyg.2013.00667

Morgan C. L. (1894). An Introduction to Comparative Psychology. London: Scott. http://dx.doi.org/10.1037/11344-000

Morin, A. (2006). Levels of Consciousness and Self-Awareness: A Comparison and Integration of Various Neurocognitive Views. Consciousness and Cognition, 15, 358-371. http://dx.doi.org/10.1016/j.concog.2005.09.006

Northoff, G. (2013). What the Brain's Intrinsic Activity Can Tell us about Consciousness? A Tri-Dimensional View. Neuroscience and Biobehavioral Reviews, 37, 726-738. http://dx.doi.org/10.1016/j.neubiorev.2012.12.004

Pisula, W. (1998). Integrative Levels in Comparative Psychology. European Psychologist, 3, 62-69. http://dx.doi.org/10.1027/1016-9040.3.1.62

Pisula, W. (2009). Curiosity and Information Seeking in Animal and Human Behavior (1st ed.). Boca Raton: BrownWalker Press.

Rochat, P. (2003). Five Levels of Self-Awareness as they Unfold Early in Life. Consciousness and Cognition, 12, 717-731. http://dx.doi.org/10.1016/S1053-8100(03)00081-3

Tobach, E. (1995). Comments on the Present Status of Comparative Psychology. Polish Psychological Bulletin, $26,203-229$.

Tobach, E. (2006). Identity of Comparative Psychology: Its Status and Advances in Evolutionary Theory and Genetics. International Journal of Comparative Psychology, 19, 129-150. http://escholarship.org/uc/item/0vv37459.pdf

Velmans, P. M. (2009). How to Define Consciousness- and How Not to Define Consciousness. Journal of Consciousness Studies, 16, 139-156. http://cogprints.org/6453/

Von Bertalanffy, L. (1950). An Outline of General System Theory. British Journal for the Philosophy of Science, 1, 134165. http://dx.doi.org/10.1093/bjps/I.2.134 


\section{Appendix}

Table A1. Levels of consciousness.

\begin{tabular}{|c|c|c|c|c|}
\hline Level & $\begin{array}{c}\text { Label } \\
\text { (short description) }\end{array}$ & $\begin{array}{l}\text { Added quality/mechanism } \\
\text { added to the lower level }\end{array}$ & $\begin{array}{l}\text { Purpose/function performed } \\
\text { for the higher level }\end{array}$ & Description of subjects ${ }^{1}$ \\
\hline VI & $\begin{array}{l}\text { Meta-consciousness II } \\
\text { I know that others also } \\
\text { know and judge }\end{array}$ & $\begin{array}{l}\text { Ability to construct mental } \\
\text { representations of other actors' } \\
\text { mental states (thoughts, } \\
\text { judgements) and to assume } \\
\text { their perspective (understand } \\
\text { their intentions, state of } \\
\text { knowledge, feelings) }\end{array}$ & $\begin{array}{l}\text { Widely understood social } \\
\text { relations. An individual } \\
\text { capable of perspective taking, } \\
\text { successfully regulates his } \\
\text { social relations, fit to enter } \\
\text { social contracts, predict how } \\
\text { others will behave in } \\
\text { changeable conditions. }\end{array}$ & $\begin{array}{l}\text { Those healthy adults who } \\
\text { achieve fullness of mental } \\
\text { development. It seems that } \\
\text { attaining this level requires } \\
\text { strong cultural training, rich } \\
\text { vocabulary, fluency in } \\
\text { verbalizing feelings and } \\
\text { psychological states. }\end{array}$ \\
\hline $\mathrm{V}$ & $\begin{array}{l}\text { Meta_consciousness I } \\
\text { I know that others feel, } \\
\text { want, (dis) like, stick } \\
\text { "with" or fight other } \\
\text { members of the group }\end{array}$ & $\begin{array}{l}\text { Ability to read emotions, what } \\
\text { another individual knows } \\
\text { (sees), others' attitudes } \\
\text { towards the subject and other } \\
\text { interaction partners. Ability to } \\
\text { personally recognize individual } \\
\text { interaction partners. }\end{array}$ & $\begin{array}{l}\text { Relations within a small }{ }^{2} \\
\text { social group. Building } \\
\text { alliances within the group. } \\
\text { Coherent in-group relations, } \\
\text { maintaining group identity } \\
\text { with regard to other group. }\end{array}$ & $\begin{array}{l}\text { The majority of human } \\
\text { population, including } \\
\text { schoolchildren. Some } \\
\text { primates and cetaceans, } \\
\text { elephants, some corvids and } \\
\text { parrots. }\end{array}$ \\
\hline IV & $\begin{array}{l}\text { Self-awareness } \\
\text { I know that I exist and } \\
\text { that there is a boundary } \\
\text { between me (my body, } \\
\text { mind) and the } \\
\text { environment }\end{array}$ & $\begin{array}{l}\text { Ability to read one’s own } \\
\text { feelings and thoughts. } \\
\text { Experiencing oneself, one's } \\
\text { body and mind as separate } \\
\text { from the rest of the reality. } \\
\text { Establishing a representation } \\
\text { of "Self” fairly stable } \\
\text { temporally and situationally }\end{array}$ & $\begin{array}{l}\text { Basic aspects of regulating } \\
\text { behavior towards others } \\
\text { within a community and in } \\
\text { interspecies relations. }\end{array}$ & $\begin{array}{l}\text { Majority of human } \\
\text { population, including } \\
\text { children under } 3 \text { years of } \\
\text { age. Significant proportion } \\
\text { of primates, cateceans, } \\
\text { carnivorans, corvids and } \\
\text { parrots. Possibly a large } \\
\text { number of animals so far not } \\
\text { assessed in this respect. }\end{array}$ \\
\hline III & $\begin{array}{l}\text { Sensory-affective } \\
\text { awareness } \\
\text { I know that I can feel and } \\
\text { that sensations are } \\
\text { aversive or pleasant }\end{array}$ & $\begin{array}{l}\text { Ability to experience pain and } \\
\text { emotions. Memorizing } \\
\text { emotions (generation of } \\
\text { acquired drives) }\end{array}$ & $\begin{array}{l}\text { Basic mechanism for } \\
\text { regulating organism's } \\
\text { behaviour towards external } \\
\text { events and objects by } \\
\text { assigning them affective } \\
\text { meaning (sign). Avoidance of } \\
\text { aversive events and desiring } \\
\text { events arousing pleasant } \\
\text { sensations. }\end{array}$ & $\begin{array}{l}\text { All vertebrates that have } \\
\text { evolved structures } \\
\text { responsible for emotional } \\
\text { responses (e.g. amygdala), } \\
\text { starting from fish. }\end{array}$ \\
\hline II & $\begin{array}{l}\text { Sensory awareness } \\
\text { I know that I sense }\end{array}$ & $\begin{array}{l}\text { Ability to experience sensory } \\
\text { stimuli perception }\end{array}$ & $\begin{array}{l}\text { Basic mechanism for } \\
\text { regulating organism's } \\
\text { behavior with respect to } \\
\text { external events and objects } \\
\text { through locating source of } \\
\text { stimulus. }\end{array}$ & $\begin{array}{l}\text { All vertebrates with } \\
\text { mesencephalon (midbrain), } \\
\text { which is the centre for } \\
\text { sensory integration in } \\
\text { ancient vertebrates. }\end{array}$ \\
\hline I & $\begin{array}{l}\text { Nonconsciousness } \\
\text { (nonconscious sensation) } \\
\text { I sense, but I do not know } \\
\text { that I sense }\end{array}$ & $\begin{array}{l}\text { Ability to experience sensory } \\
\text { stimuli and respond to them }\end{array}$ & $\begin{array}{l}\text { Adaptive automatisms (taxes, } \\
\text { tropisms). }\end{array}$ & $\begin{array}{l}\text { All animals equipped with } \\
\text { nervous system and sensory } \\
\text { organs }\end{array}$ \\
\hline
\end{tabular}

${ }^{1}$. For the sake of simplicity, the animal world is treated as vertebrates only.

${ }^{2}$. Without getting into a detailed discussion of how large small groups are: I mean groups from several to several dozen (fewer than 50) individuals. 